\title{
Solar thermoelectric field plus photocatalysis for efficient organic synthesis exemplified by toluene to benzoic acid
}

\author{
Yanji Zhu, ${ }^{[+]}{ }^{a}$ Huaiyuan Wang, ${ }^{[+]}{ }^{a}$ Baohui Wang, ${ }^{*}$ Xuelin Liu, ${ }^{a}$ Hongjun Wu ${ }^{a}$ and Stuart Licht ${ }^{*} b$ \\ ${ }^{a}$ Institute of New Energy Chemistry and Environmental Science, College of Chemistry and Chemical Engineering, \\ Northeast Petroleum University, Daqing 163318 (PR China). \\ ${ }^{b}$ Department of Chemistry, George Washington University, Washington DC 20052 (USA).
}

\begin{abstract}
The Solar Thermal Electrochemical Process synthesis of benzoic acid is an efficient way for organic synthesis based upon solar energy utilization. Graphite and platinum anodes have been developed with high yield and selectivity of benzoic acid. In this article, we present the first demonstration of the solar Thermal-Electro-Photo field for efficient benzoic acid synthesis by using $\mathrm{TiO}_{2}$ nanotubes electrode. By adjusting the three-solar field process, toluene is oxidized at the surface of the photoactive, electrically driven, heat activated $\mathrm{TiO}_{2}$ nanotubes electrode. Results showed that, the synergistic effect of the three fields was found for enhancement of toluene oxidation at $\mathrm{TiO}_{2}$ electrode. The yield of benzoic acid and conversion of toluene is greatly improved with temperature, and arriving to $26.1 \%$ and $62.6 \%$ at $90^{\circ} \mathrm{C}$, respectively. In this process, solar thermal decreases the electrolysis potential of toluene oxidation. Hydroxyl, Carboxyl and $-\mathrm{O}-\mathrm{OH}$ groups, as well as the emergence of TiO-C bond at the surface of the $\mathrm{TiO}_{2}$ nanotubes electrode, lead to an increased UV and visible absorption and a significant enhancement of $\mathrm{TiO}_{2}$ photocatalytic properties to increase the yield of benzoic acid. Simultaneously, an applied solar electric potential promotes the separation of photogenerated electrons and holes. As a result the efficiency of $\mathrm{TiO}_{2}$ photocatalysis enhanced.
\end{abstract}

KEYWORDS: Photocatalysis, $\mathrm{TiO}_{2}$ nanotubes, Solar, Thermoelectric, Benzoic acid synthesis

\section{Introduction}

The increase in consumption of fossil fuels, its eventual depletion and its associated environmental pollution have prompted a careful look at the issues dealing with our energy supply and demand. ${ }^{[1]}$ The buildup of atmospheric carbon dioxide and its climate change consequences, and the ongoing, increasing demand for energy is forcing us to seek environmentally clean alternative energy resources. ${ }^{\text {[2] Solar }}$ energy contributes an increasing role in energy production owing to its abundance, cost-competitiveness, and low associated carbon emissions, and great efforts have been devoted to develop new solar energy conversion systems. The direct conversion of solar energy to chemical energy for the production of renewable and nonpolluting materials remains a great and fascinating challenge for scientists. ${ }^{[3-4]}$ A promising method of solar energy conversion for the synthesis of organic chemicals is artificial photosynthesis, but the efficiency of sunlight driven syntheses has remained low, and an alternative to light (alone) activated processes is needed.

The solar thermal electrochemical process, is an alternative solar energy conversion process. It achieves a high efficiency by matching solar-to-thermal and solar-to-electrical conversion for a specific molecular reaction or solar-to-chemical process. The process uses the full spectrum of sunlight, including the subbandgap (IR) spectrum that not accessible to solar cells, to lower the energy and facilitates the kinetics of useful endothermic chemical reactions. ${ }^{[5-8]}$ Solar thermoelectric organic synthesis, as an efficient solar thermal electrochemical process, and has been used in benzoic acid synthesis from toluene, $\left.{ }^{[9,} 10\right]$ as simultaneously driven by a thermal collector and a photovoltaic.

In general, the direct oxidation of toluene is difficult to carry out, it needs harsh condition such as high temperature, high pressure or promotion by a catalyst. [11] Solar thermoelectric process provides an improved synthetic pathway by coupling solar electronic and solar thermal energies. Here we address the question of whether this process can be further improved by coupling solar UV, solar electronic and solar thermal energies at the same time, as solar is compatible with the high bandgap of $\mathrm{TiO}_{2}$ which is known as photocatalyst.

Recently, solar energy conversion systems based on nanostructured elements have attracted considerable interest. ${ }^{[12,}$ 13] As the nanostructured materials such as nanocrystals or quantum dots, nanotubes, nanorods, and nanowires, can significantly improve charge collection efficiency. ${ }^{[14,15]}$ Among

\footnotetext{
* Corresponding author. Tel.: +86 459 6503498; fax: +86 4596503498 Baohui Wang (wangbh@nepu.edu.cn) and Stuart Licht (slicht@gwu.edu).

${ }^{[+]} \mathrm{Y}$ Zhu and $\mathrm{H}$ Wang contributed equally to this work
} 
various sunlight responsive materials, titanium dioxide $\left(\mathrm{TiO}_{2}\right)$ is a widely studied inexpensive, commercially available, non-toxic and chemically stable photocatalyst. ${ }^{[16-18]}$ Apart from water treatment applications, $[19,20] \mathrm{TiO}_{2}$ has been extensively employed in air purification. ${ }^{[21,22]} \mathrm{TiO}_{2}$ has three metastable phases: rutile, anatase and brookite. The anatase crystalline phase is desired due to its stronger response under UV irradiation. ${ }^{[23]}$ The wide bandgap energy of $\mathrm{TiO}_{2}$ means higher energy from UV light is required to excite electrons to produce hydroxyl radicals, which is the key to the photoreaction of chemicals in the presence of oxygen. ${ }^{[24,25]}$ Arrays of $\mathrm{TiO}_{2}$ nanotubes with anatase crystalline have been widely used to facilitate optical absorption and collection of UV. ${ }^{[26]}$

Herein, we report a more comprehensive solar thermoelectric process for solar energy utilization, a reaction driven simultaneously by three-solar field, in which solarthermal, solar-electricity and solar-photo has been used in one system for benzoic acid synthesis from toluene. In this 3-field mode, $\mathrm{TiO}_{2}$ nanotubes are utilized as the electric and light driven anode. The photoactive electrode is prepared by calcinating the anodized $\mathrm{TiO}_{2}$ nanotubes at the temperature of $450^{\circ} \mathrm{C}$ to obtain a large surface area and strong activity of photocatalysis. The reactant (toluene) was oxidized (to benzoic acid) at the $\mathrm{TiO}_{2}$ nanotubes film electrode. The conversion of benzoic acid increased with the combined application of solarthermal (higher temperature), an applied stable solar photovoltage, and solar photons. The $\mathrm{TiO}_{2}$ nanotube electrode is characterized by SEM, EDS, FTIR and XRD. The composition of products from toluene oxidation (benzyl alcohol, benzaldehyde, and benzoic acid) is determined by gas chromatography (GC). The mechanism of the photocatalysis of toluene at $\mathrm{TiO}_{2}$ nanotube electrode is explored, and the synergistic effect of solar thermal, solar electricity and UV part of sunlight on the reaction process of benzoic acid formation was demonstrated for the first time.

The synthesis rate of benzoic acid is $0-8.9 \%$ with the application of a single solar field (either photo-activated, the separate application of solar thermal or solar electronic energy) and increases to $26.1 \%$ in the three-field of solar energy process. In this three-field experiment, the overall conversion of toluene reaches $62.6 \%$ at $90^{\circ} \mathrm{C}$ with the aid of $1.0 \mathrm{~V}$ stable voltage of photovoltaic and UV sunlight. All energy for this benzoic acid synthesis at $\mathrm{TiO}_{2}$ nanotubes electrode comes from solar thermal, solar electricity and solar photo, these three fields of solar energy process are well matched to function simultaneously with each other.

\section{Experimental Section}

\subsection{Chemicals and materials}

A $2 \mathrm{~mm}$ thick titanium sheet (99.6\%, Stream Chemicals) was cut into pieces of $20 \times 10 \mathrm{~mm}^{2}$. Ethylene glycol $\left(\left(\mathrm{CH}_{2} \mathrm{OH}\right)_{2}, \mathrm{EG}\right)$, ammonia fluoride $\left(\mathrm{NH}_{4} \mathrm{~F}\right)$, acetone $\left(\mathrm{CH}_{3} \mathrm{COCH}_{3}\right)$ were purchased from Xinlian Organics and used as received. All aqueous solutions were prepared using deionized (DI) water with a resistivity of $18.2 \mathrm{MU} \mathrm{cm}$ that was prepared by a Millipore system. Benzoic acid $\left(\mathrm{C}_{6} \mathrm{H}_{5} \mathrm{COOH}\right.$, ZT Co., LTD, 99.5\%), toluene $\left(\mathrm{C}_{6} \mathrm{H}_{5} \mathrm{CH}_{3}, \mathrm{YX}\right.$ Chemical Co., LTD, 99.5\%), Benzaldehyde $\left(\mathrm{C}_{6} \mathrm{H}_{5} \mathrm{CHO}, \mathrm{CL}\right.$ Co., LTD, 98.5\%), Sodium dodecyl benzene sulfonate $\left(\mathrm{C}_{18} \mathrm{H}_{29} \mathrm{NaO}_{3} \mathrm{~S}, \mathrm{XW}\right.$ Co., LTD), Sodium hydroxide (NaOH, PK Chemical Co., LTD, 99.5\%) and Sulfuric acid $\left(\mathrm{H}_{2} \mathrm{SO}_{4}\right.$, LT Chemical Co., LTD, 98\%) were used in the solutions.

\subsection{Preparation of $\mathrm{TiO}_{2} \mathrm{NTs}$}

The $\mathrm{TiO}_{2}$ nanotubes electrode on the $\mathrm{Ti}$ substrate was fabricated in the following manner. The $\mathrm{TiO}_{2}$ NTs film was obtained using the anodization process in an electrolyte solution containing $0.2 \mathrm{~g}$ $\mathrm{NH}_{4} \mathrm{~F}, 1.2 \mathrm{~mL}$ deionized water and $60.0 \mathrm{~mL}$ glycol. Prior to anodization, the $\mathrm{Ti}$ sheet was first degreased by sonicating in acetone, ethanol and room-temperature deionized water for 15 minute respectively. The anodization was carried out by using a conventional two-electrode system with the Ti sheet as an anode and a Pt gauze (Aida, 52 mesh) as a cathode, the Ti sheet was anodized at $50.0 \mathrm{~V}$ for $30 \mathrm{~min}$. After the anodization, the prepared $\mathrm{TiO}_{2}$ NT samples were cleaned with DI water and dried in air. Finally, the sample was annealed at $450^{\circ} \mathrm{C}$ for $2.0 \mathrm{~h}$ with heating and cooling rates of $10{ }^{\circ} \mathrm{C} \mathrm{min}-1$, the anatase $\mathrm{TiO}_{2}$-film can be fabricated.

\subsection{Solar Thermal-Electricity-Photo Process for benzoic acid synthesis}

The synthesis of benzoic acid was experimentally characterized in a synergy of combined solar thermal, solar electricity, and solar photo energies. The as-prepared $\mathrm{TiO}_{2}$ electrode $\left(1.0 \times 1.0 \mathrm{~cm}^{2}\right)$ and Pt-counter electrode $\left(1.0 \times 1.0 \mathrm{~cm}^{2}\right)$ were assembled into a sandwich-type electrolyzer. A Keithley 2601 source meter was used to collect data, and collimated light $(\lambda>300 \mathrm{~nm}, 100$ $\mathrm{mW} / \mathrm{cm}^{2}$ ) from an Oriel $300 \mathrm{~W}$ xenon arc lamp was used as the light source to simulate AM 1.5 illumination $\left(100 \mathrm{~mW} / \mathrm{cm}^{2}\right)$. The photooxidation activity of $\mathrm{TiO}_{2}$ nanotube electrode was evaluated by matching the photoreaction of toluene experimental setup with the coupling mode of solar thermal and solar electricity process for benzoic acid synthesis as previously detailed, ${ }^{[9]}$ and in this study also with, and without, illumination under UV light. Before experimentation, the $100 \mathrm{~mL}$ solution of the $0.05 \mathrm{M}$ sulfuric acid and $0.001 \mathrm{M}$ surfactant is placed into the electrolysis cell and was stirred for $1.0 \mathrm{~h}$ in the dark to reach the adsorption-desorption equilibrium, and then the toluene is added to the reaction chamber with $200 \mathrm{ppm}$ at the voltage of $1.0 \mathrm{~V}$ from solar electricity. The initial photocurrent at an applied $1.0 \mathrm{~V}$ photopotential increases from $0.01 \mathrm{~mA} \mathrm{~cm}^{-2}$ at $30^{\circ} \mathrm{C}$ to $0.15 \mathrm{~mA}$ $\mathrm{cm}^{-2}$ at $90^{\circ} \mathrm{C}$. Repeat the above experiment by illuminating the devices, and control the temperature $\left(30^{\circ} \mathrm{C}, 60^{\circ} \mathrm{C}\right.$ or $\left.90^{\circ} \mathrm{C}\right)$ for 0.5 1.0 hours until the current decreases tenfold, at which point the electrolysis can be terminated, and the outdoor experimental apparatus are shown in Figure S1. The separation of the crude product has been detailed in our previous article. ${ }^{[9]}$ The product can be characterized by Gas Chromatography, and the analysis of SEM, FTIR, XRD, EDS of $\mathrm{TiO}_{2}$ electrode has been carried out.

The single field experiments, including solar thermal, solar electrical, and solar photo (directly usage of sunlight) field driven process for benzoic acid synthesis, are also carried out on the solar thermal-electricity-photo process. The configuration of the electrolyte, reactant and other operations are the same thing of the 3-field. Similar situation applies to the coupling effect of solar energy (ST, SE, SP) for benzoic acid synthesis, that is the efficiency of pair-wise combinations (simultaneous application of two of the three individual) of solar energy field.

\subsection{Characterization of $\mathrm{TiO}_{2} \mathrm{NTs}$}

IR-spectra were measured in $\mathrm{KBr}$ pellets from $4000-400 \mathrm{~cm}^{-1}$ using a Tensor 27 FTIR spectrometer to detect the changes produced by groups at the surface of the $\mathrm{TiO}_{2}$ electrode before and after benzoic acid synthesis with synergistic of solar thermal, 
solar electricity and solar photo. The morphologies of the $\mathrm{TiO}_{2}$ electrode were obtained by scanning electron microscopy (SEM, Quanta 200) and the compositions on the film were measured by Energy Dispersive Spectrometer (EDS). The crystalline structure was analyzed by X-ray diffraction (XRD, $\mathrm{D} / \mathrm{max}-2200 \mathrm{PC}$, using $\mathrm{Cu} \mathrm{Ka}$ radiation, with the samples scanned from 10 to $80^{\circ}$ in the steps of $0.02^{\circ}$ at each point).

\subsection{Product analysis}

In order to measure the compositional of benzyl alcohol, benzaldehyde, and benzoic acid in the product quantitatively, the synthesized product was collected and analyzed using gas chromatography (GC-14C) equipped with a flame ionization detector and a $30 \mathrm{~m} \times 0.25 \mathrm{~mm} \times 0.33 \mu \mathrm{m}$ FFAP capillary column. The reaction yield (in percent) was calculated by comparing the initial moles of toluene to the measured moles of either benzoic acid or intermediates produced in the electrolysis. The selectivity of benzoic acid (in percent) was determined by comparing the moles of benzoic acid produced to total moles (of intermediates and benzoic acid) produced.

\section{Results and Discussion}

\subsection{Mode of solar thermoelectric plus photocatalysis of} benzoic acid synthesis

As illustrated in Scheme S1, benzoic acid can be synthesized by combining the solar thermoelectric mode with the photocatalysis oxidation of toluene at the electrode. During the synthesis reaction at $\mathrm{TiO}_{2}$ nanotube electrode, all of the energy comes from solar and without other form of energy, and the solar-thermal, solar-electro and UV portions of sunlight are synergistically mixed to optimize product yield and product specificity. For example, the reaction of toluene oxidation is endothermic, and the addition of solar-thermal lowers the electrolysis potential, while the application of a photopotential and photo-activation at $\mathrm{TiO}_{2}$ electrode are favorable to raise the efficiency of solar thermoelectric benzoic acid synthesis. During the oxidation of toluene at $\mathrm{TiO}_{2}$ nanotube electrode, thermochemistry, electrochemistry and photochemistry of the reactant work together, all the three fields are generated from solar and are matched with each other for higher yield of product.

\subsection{Efficiency of benzoic acid synthesis by solar energy}

\subsubsection{Conversion of benzoic acid for single field of solar}

In this study we explore here, three ways to use the sun's energy related to three spectral regions: (1) solar-to-thermal (ST) comprises sub-band gap energy and consists of longer wavelength light conducive to focus concentration and efficient absorption as heat, (2) solar-to-electrical (SE) energy comprises super-band gap energy which can be converted to electricity by photovoltaics and consists of visible wavelength light, and (3) solar-to-photo (directly usage of sunlight, SP) and in particularly energetic UV/near UV light which is conducive to initiating photo driven chemical reactions at the high bandgap materials such as $\mathrm{TiO}_{2}$.

Fig. 1 presents the measured reaction of toluene and its conversion to benzoic acid and intermediates (benzaldehyde and benzyl alcohol) under the three field of solar energy. It is evident that via the ST field route at $90^{\circ} \mathrm{C}$, as shown on the left lower side of Fig. 1, the main constitute of the product of toluene oxidation is benzaldehyde with a yield of $6.9 \%$, and there is trace of benzyl alcohol, but there is no benzoic acid, and the overall conversion of toluene is $7.2 \%$. Instead with the individual application of either SE or SP fields the conversion gets larger. As shown in the lower middle or right portions of Fig. 1 respectively for either SE (under a $1 \mathrm{~V}$ photovoltaic generated photobias) or SP driven toluene oxidation, the conversion of toluene is $24.8 \%$ and $23.7 \%$. Unlike the ST reaction route, in these SE and SP syntheses each of the three products (benzaldehyde, benzyl alcohol and benzoic acid) has been detected. Therefore the synthesis of benzoic acid can be processed by utilization of solar energy with single ST, SE or SP field, but with a low toluene conversion of $25 \%$ or less.

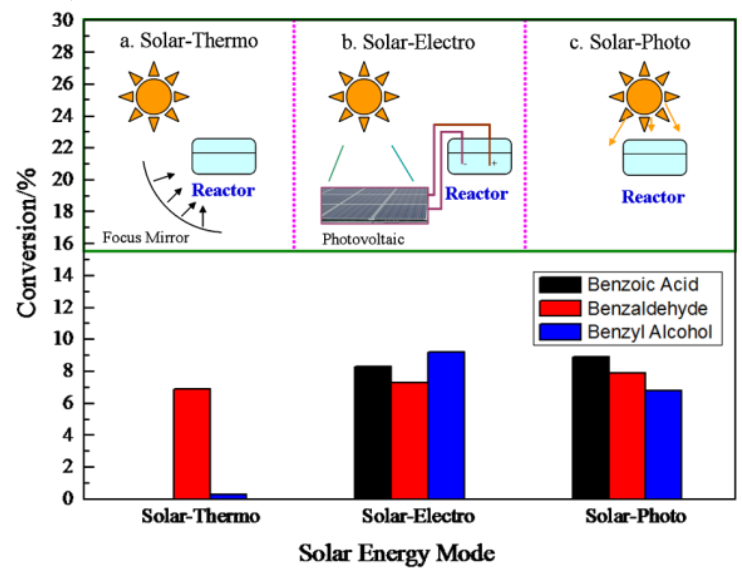

Fig. 1 Single field for benzoic acid synthesis and the corresponding conversion of toluene to: benzoic acid, benzaldehyde, and benzyl alcohol, \%

\subsubsection{Coupling fields for benzoic acid synthesis by using solar energy}

In order to investigate the coupling effect of solar energy (ST, SE, $\mathrm{SP})$ for benzoic acid synthesis, the efficiencies of pair-wise combinations of (simultaneous application of two of the three individual, ST, SE or SP) solar energy field have been studied. Table S1 shows the yield of benzoic acid, benzaldehyde, benzyl alcohol and the conversion of toluene at different coupling fields of solar energy. It can be seen that, at different coupling modes (SE-SP, SP-ST, ST-SE) of solar energy for toluene oxidation, the yield of benzoic acid and the conversion of toluene increased obviously than that of the single solar energy field. For the pairwise of ST, SE and SP, the efficiency for toluene oxidation increased, they cooperate with each other for efficient benzoic acid synthesis.

\subsubsection{Solar thermal-electro-photo field for benzoic acid synthesis}

For the simultaneous application of three solar field, ST, SE and $\mathrm{SP}$, that a synergy is observed for the oxidation of toluene, in which the conversion is greater than that of the combined individual reactions. As seen in Fig. 2, with the aid of solar electro $(1.0 \mathrm{~V})$ and UV of sunlight, the yield of benzoic acid reached $11.5 \%, 20.8 \%, 26.1 \%$ at temperature of 30,60 and $90{ }^{\circ} \mathrm{C}$ (by solar thermal), and the conversion of toluene also increased sharply, which runs up to $34.7 \%, 55.5 \%, 62.6 \%$ respectively. In particular, this latter conversion rate of $62.6 \%$ is greater than the sum of individual conversions of toluene, $55.7 \%(7.2 \%$ (ST) $+24.8 \%$ $(\mathrm{SE})+23.7 \%(\mathrm{SP})$ ), and much higher than any of the synthetic routes accomplished under the two coupling solar fields. The oxidation of toluene is endothermic, the increasing input of solar thermal on the reaction is beneficial not only for the 
decreasement of thermodynamic in redox potential, but also for the enhancement of the reaction kinetics. [9] The stable potential, 1.0V, from solar electro can prompt the transfer of electron; and the UV of sunlight provides energetic radiation for photocatalysis at the $\mathrm{TiO}_{2}$ electrode. Consequently, the synergism of solar thermal, solar electro and UV of sunlight provides enough energy for toluene oxidation. As detailed in mechanism analysis, with the 3-field process the active state of the reaction transition process has been formed.

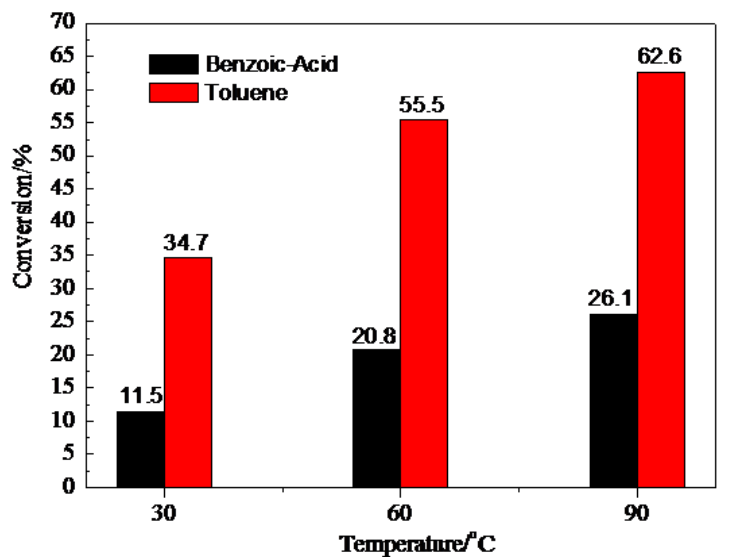

Fig. 2 Yield of benzoic acid at the matched fields of solar thermalelectro-photo and the corresponding conversion of toluene, $\%$

There are benzoic acid, benzaldehyde and benzyl alcohol in the product, the selectivity under various synthetic conditions of every product component is shown in Table S2. It can be seen that the selectivity of benzoic acid and benzaldehyde increases with temperature, but for benzyl alcohol it is decreased. That is due to the application of heating (more of solar thermal energy) with the aid of solar electro and UV of sunlight, in which case more of benzyl alcohol oxidized to benzaldehyde and then onto benzoic acid. Therefore, in solar thermoelectric organic, ${ }^{[9]}$ matching fields of solar energy for organic synthesis, plus photocatalysis of $\mathrm{TiO}_{2}$ anode for benzoic acid synthesis provides a high efficient pathway for utilization of solar energy.

\subsection{Morphology of $\mathrm{TiO}_{2}$ nanotubes electrode used for in solar thermoelectric organic synthesis}

As illustrated in Fig. 3, the anodization of $\mathrm{Ti}$ in fluoride electrolytes can result in the formation of a nanotube morphology, ${ }^{[27]}$ the mean diameter of the as-prepared $\mathrm{TiO}_{2}$ nanotubes ranges from $30-120 \mathrm{~nm}$, as shown in Fig. 3(a) and many nano-pillars can be seen from a cross-section of the asprepared $\mathrm{TiO}_{2}$ nanotubes anode in Fig. 3(a'), the wall of the $\mathrm{TiO}_{2}$ nanotube is double-deck, and it is composed of $\mathrm{TiO}_{2}$ nanoparticles with diameter of $2-5 \mathrm{~nm}$, which can become the reactive sites of the formation of benzoic acid from toluene, all of these make the $\mathrm{TiO}_{2}$ nanotubes possess excellent photocatalysis activities. ${ }^{28,29]}$

The morphology of the $\mathrm{TiO}_{2}$ nanotubes electrode after being used as anode under thermal-electro-photo field for benzoic acid synthesis at temperature of 30,60 , and $90^{\circ} \mathrm{C}$ has been shown in Fig. $3(b-d)$. It can be seen that the surface of the electrode becomes smoother, while the diameter of $\mathrm{TiO}_{2}$ nanotube decreases with the increase of temperature $(30,60$, $90^{\circ} \mathrm{C}$ ) to approximately 155,115 , and $92 \mathrm{~nm}$, there are many of nano-particles observed, situated at the wall of nanotubes. At the same time, the cross-section morphologies of the $\mathrm{TiO}_{2}$ nanotubes are shown in Fig. $3\left(b^{\prime}-d^{\prime}\right)$, and the length of the
$\mathrm{TiO}_{2}$ nanotubes increase from $2.1,2.8$ to $3.3 \mu \mathrm{m}$, which would act to enhance the photocatalysis of $\mathrm{TiO}_{2}$. ${ }^{[30]}$ The conversion of toluene also increases with temperature as shown in Fig. 2. The nano-pillars at the side walls of $\mathrm{TiO}_{2} \mathrm{NTs}$ change to the ripples, but the length becomes smaller and they are nearly attached to the surface. This formed "nanobamboos" morphology (NBs as reports as the literature) has been shown to be beneficial for the improvement of the $\mathrm{TiO}_{2}$ photocatalysis. ${ }^{[31]}$

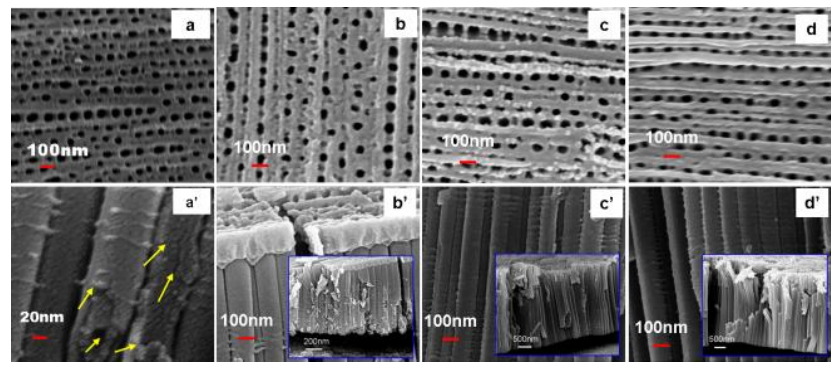

Fig. 3 Morphology and the cross-section of $\mathrm{TiO}_{2}$ nanotubes electrode for benzoic acid synthesis at different reaction conditions: (a) and (a') asprepared $\mathrm{TiO}_{2}$ nanotubes; (b-d) and (b'-d') anode used as the matched solar thermal-electro-photo field for benzoic acid synthesis at 30, 60 and $90^{\circ} \mathrm{C}$

3.4 Analysis of $\mathrm{TiO}_{2}$ nanotubes used for anode of solar thermoelectric benzoic acid synthesis

\subsubsection{EDS analysis of $\mathrm{TiO}_{2}$ nanotubes anode}

The Energy-Dispersive X-ray Spectroscopy (EDS) analysis of the $\mathrm{TiO}_{2}$ nanotubes anodes is shown in Table S3. Results showed that the elements of the $\mathrm{TiO}_{2}$ nanotubes electrode are carbon(C), oxygen (O) and Titanium ( $\mathrm{Ti}$ ). The appearance of $\mathrm{C}$ supports the change of the $\mathrm{TiO}_{2}$ electrode before and after electrolysis at various temperatures. It can be seen that the atom percentage of $\mathrm{C}$ and $\mathrm{O}$ of the as-prepared $\mathrm{TiO}_{2}$ nanotubes is $5.4 \%$ and $67.1 \%$ respectively, which comes from the solvent during the anodization of $\mathrm{TiO}_{2}$. While after it was used as anode for benzoic acid synthesis at the solar three-field mode, the atom percentage of $\mathrm{C}$ reached to $7.2 \%, 10.2 \%$ and $12.2 \%$, (originating from the surfactant), at the temperature of 30,60 and $90^{\circ} \mathrm{C}$ respectively; the atom percentage of $O$ decreased from $65.1 \%$ to $62.7 \%$ and $61.0 \%$. Furthermore, from the last column, it can be seen that the atomic composition of $\mathrm{C}$ increased with temperature, from 0.20 to 0.46 , but the atomic composition of $\mathrm{O}$ decreased from 2.44 to 2.28 , which is consistent with $\mathrm{C}$ having replaced some of the $\mathrm{O}$ embedded in the $\mathrm{TiO}_{2}$ surface in the formation of benzoic acid.

\subsubsection{FTIR analysis of $\mathrm{TiO}_{2}$ nanotubes electrode}

The FTIR spectrum of the $\mathrm{TiO}_{2}$ nanotubes before and after used as the anode of the combined field of solar thermal-electro-photo is shown in Fig. 4. Relevant features in the spectrum are the strong sharp band at $1691 \mathrm{~cm}^{-1}$ corresponding to the stretching vibration of the hydrogen bonded $\mathrm{C}=\mathrm{O}$ group at the surface of $\mathrm{TiO}_{2}$, and those around $1384 \mathrm{~cm}^{-1}$ due to the vibration modes of the COO group. ${ }^{[32]}$ The bands at 1157,1085 , and $1047 \mathrm{~cm}^{-1}$ (stretching Ti-O-C) together with the appearance of intense bands around 872 and $714 \mathrm{~cm}^{-1}$ in spectrum indicate the hydrolysis of the alkoxide and the formation of $\mathrm{Ti}-\mathrm{O}$ and $\mathrm{Ti}-\mathrm{O}-\mathrm{Ti}$ bonds, respectively. ${ }^{[33]}$ But in spectrum $b$, the fading of the bands at 872 and $714 \mathrm{~cm}^{-1}$ and the enhancing of the bands at $1157 \mathrm{~cm}^{-1}$ identifies the formation of $\mathrm{Ti}-\mathrm{O}-\mathrm{C} .{ }^{[34]}$ The presence of $\mathrm{Ti}-\mathrm{O}-\mathrm{C}$ band indicates $\mathrm{TiO}_{2}$ and $\mathrm{C}$ (originating from the surfactant) has good contact through chemical bonds, that favors the charge 
transfer of $\mathrm{TiO}_{2}$ and extends its visible band upon light excitation, ${ }^{[35]}$ and contributes to the formation of benzoic acid.

The $\mathrm{OH}$ stretching mode of the hydroxyl group corresponding to the characteristic band of the $\mathrm{Ti}-\mathrm{OH}$ group is mainly responsible for the broad band from 3340 to $3202 \mathrm{~cm}^{-1}$, that became narrow after using as the anode in the solar thermoelectric mode, and a shoulder at $1654 \mathrm{~cm}^{-1}$ over the $1691 \mathrm{~cm}^{-1}$ signal appeared due to the $\mathrm{O}-\mathrm{OH}$ bending mode.

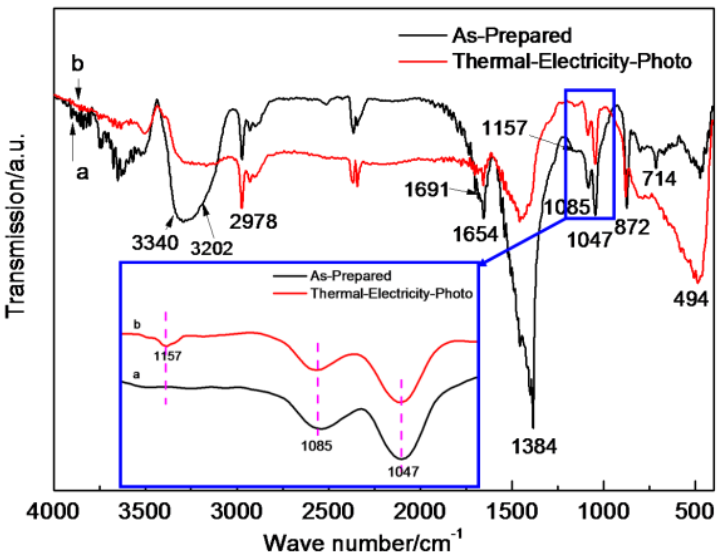

Fig. $4 \mathrm{FTIR}$ of $\mathrm{TiO}_{2}$ nanotubes anode at reaction condition of: a. asprepared b. solar thermal-electro-photo

\subsubsection{XRD analysis of $\mathrm{TiO}_{2}$ nanotubes electrode}

The XRD of $\mathrm{TiO}_{2}$ nanotubes, as prepared and after used as the photoanode for benzoic acid synthesis, is shown in Fig. 5. XRD measurements revealed that all $\mathrm{TiO}_{2}$ samples were successfully converted into crystalline forms after thermal annealing at $450^{\circ} \mathrm{C}$ in air. The emergence of $A$ peak suggests the formation of the photocatalysis anatase $\mathrm{TiO}_{2}$, while the additional peaks originated from the $\mathrm{Ti}$ substrate also can be seen. In Fig. 5 a, at the surface of the as-prepared $\mathrm{TiO}_{2}$ electrode, there are weaker peaks evident for $\mathrm{Ti}_{2} \mathrm{O}, \mathrm{Ti}_{6} \mathrm{O}, \mathrm{Ti}_{2} \mathrm{O}_{3}$, $\mathrm{Ti}_{1.8} \mathrm{O}_{3}$, while when they are used as anode for benzoic acid synthesis at the mode of solar thermoelectric process plus photocatalysis, their intensity increases with temperature, Fig. 5 b-d.

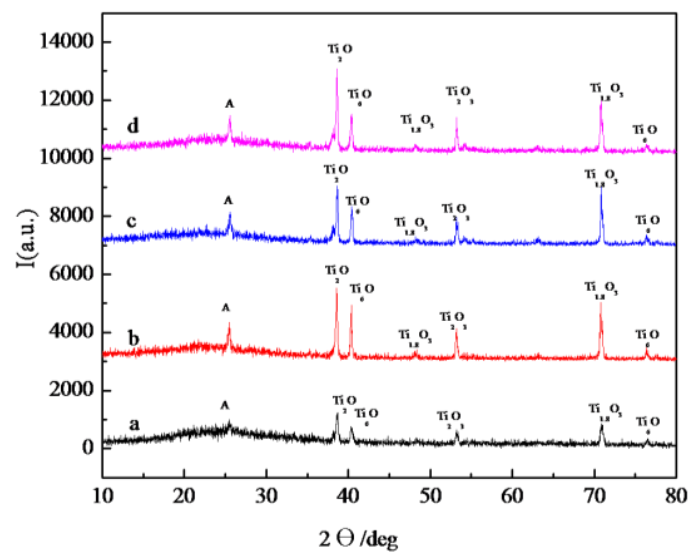

Fig. 5 XRD patterns of $\mathrm{TiO}_{2}$ nanotubes anode used at different conditions of: $a$. as-prepared and $b-d$ for the combined field of solar thermal-electro-photo of 30,60 and $90{ }^{\circ} \mathrm{C}$

As for bulk $\mathrm{TiO}_{2}$, optical and electronic properties of $\mathrm{TiO}_{2}$ nanotubes are strongly depend on bulk or surface structural defects. Oxygen vacancies are quite common in $\mathrm{TiO}_{2}$, their presence and behavior can significantly affect the electric and optical properties of the materials. When $\mathrm{TiO}_{2}$ is reduced, it forms $\mathrm{Ti}^{3+}$ and an oxygen vacancy (OV). ${ }^{[36]}$ The two electrons coming from the removed oxygen are redistributed within the structure, and thereby the electronic conductivity of $\mathrm{TiO}_{2}$ is enhanced (self-doping). The resulting electronic $\mathrm{Ti}^{3+}$ and OV states lie in the band gap of $\mathrm{TiO}_{2}$ (typically 0.3 and $0.7 \mathrm{eV}$ from the conduction band of anatase) ${ }^{[37]}$ and are responsible for stronger changes in the electronic conductivity and optical properties. The unsaturated $\mathrm{Ti}$ cations, such as $\mathrm{Ti}^{3.3+}, \mathrm{Ti}^{3+}, \mathrm{Ti}^{+}, \mathrm{Ti}^{0.3+}$ on the $\mathrm{TiO}_{2}$ surface, can be produced for the splitting off $\mathrm{O}_{2}$ or $\mathrm{H}_{2} \mathrm{O}$ from terminal oxide or hydroxide groups and bridged oxide and $\mathrm{Ti}^{3+}$ states. ${ }^{[38]}$ Moreover, the increased concentration of $\mathrm{Ti}^{3+}$ and OVs is postulated to promote the generation of hydroxyl radicals and thus accelerate the oxidation of toluene, and strengthen the process by coupling the solar thermal and solar electro chemistry. [39]

\subsection{Mechanism of toluene oxidation at the mode of sola thermoelectric plus photocatalysis}

\subsubsection{Solar energy for benzoic acid synthesis}

As shown in scheme 1, the solar spectrum is divided into the UV band $(0.15-0.4 \mu \mathrm{m})$, the visible band $(0.4-0.75 \mu \mathrm{m})$ and the infrared band $(0.75-4.0 \mu \mathrm{m})$, which comprises approximately $7 \%, 50 \%$ and $43 \%$ of the solar energy respectively. ${ }^{[40]}$ To utilize the energy in UV band, the selection of the photosensitive materials is the key factor, in which case the UV band can be used as the photoactive zone for chemical process. In the visible band, the sunlight is converted to electricity, this photovoltaic solar energy can be used as generated or stored in and released whenever it is needed. ${ }^{[41]}$ And in the infra-red band, much of the radiation can be converted to thermal, solar collector is the necessary affiliation for the system. The conversion of the three forms of solar spectra to photo, electricity and thermal is 93\% (absorption of near UV photons from sunlight), $14-40 \%$ (photon to electron conversion efficiencies via various photovoltaics) and $65-80 \%$ (efficiency of absorption of solar thermal energy) respectively. ${ }^{[42]}$ Hence, if all of the solar spectrum radiation can be used in a reaction and with high efficiency, it is a fascinating way of utilization of solar energy In the mode of solar thermoelectric plus photocatalysis, the solar energy can be simultaneously, effectively and synergistically utilized effectively.

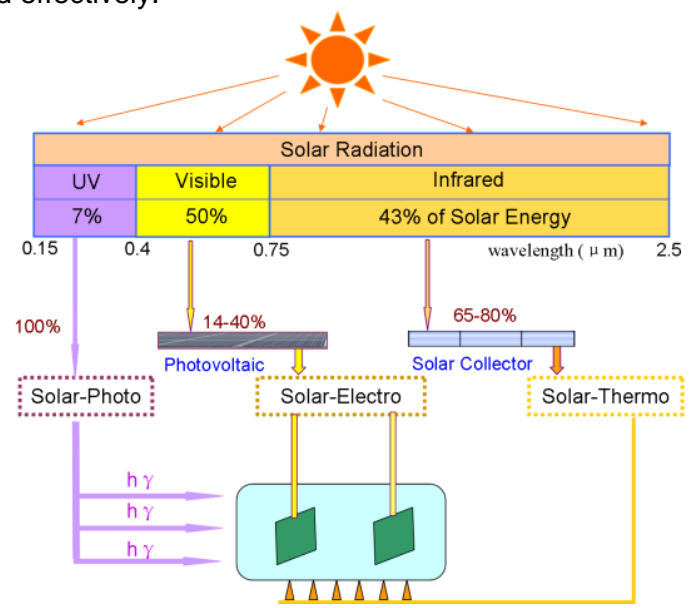

Scheme 1 Synergistic of solar thermal, solar electro and solar photo for reaction

\subsection{2 $\mathrm{TiO}_{2}$ nanotube electrode for benzoic acid synthesis}

As discussed in Figure 2, the yield of benzoic acid from toluene oxidation at $\mathrm{TiO}_{2}$ nanotubes electrode increases with temperature and reaches $26.1 \%$ at temperature of $90^{\circ} \mathrm{C}$ in solar thermoelectric process plus photocatalysis, the reaction process is shown in 
Scheme 2. The $\mathrm{TiO}_{2}$ nanotubes are arranged regularly at the $\mathrm{Ti}$ substrate, as shown in Fig. 3 a, the wall of the $\mathrm{TiO}_{2}$ nanotubes with substantially of nanoparticles and a double-deck structure is obtained, which is beneficial for improving the surface area of the $\mathrm{TiO}_{2}$ anode. The toluene is oxidized at the surface of $\mathrm{TiO}_{2}$ electrode, or precisely at the surface of the $\mathrm{TiO}_{2}$ nanoparticles. The higher yield of benzoic acid is attributed to two factors: the first is the specific surface area of $\mathrm{C}-\mathrm{TiO}_{2},{ }^{[43]}$ which forms during the reaction mainly incorporated by organic (surfactant) decomposition, adsorption, and overgrowth, the $\mathrm{Ti}$ oxyhydroxide species stem from precipitated $\mathrm{Ti}$ ions ejected from the oxide, see Fig. 5, offering more active adsorption sites and photoreaction centers; and the second is for the abundance of $\mathrm{Ti}^{3+}$ sites and OV that has been confirmed in our previous article, ${ }^{[4]}$ which serves as energetically favorable sites for electron transfer to toluene at the surface of $\mathrm{C}-\mathrm{TiO}_{2}$, see Fig. 5.

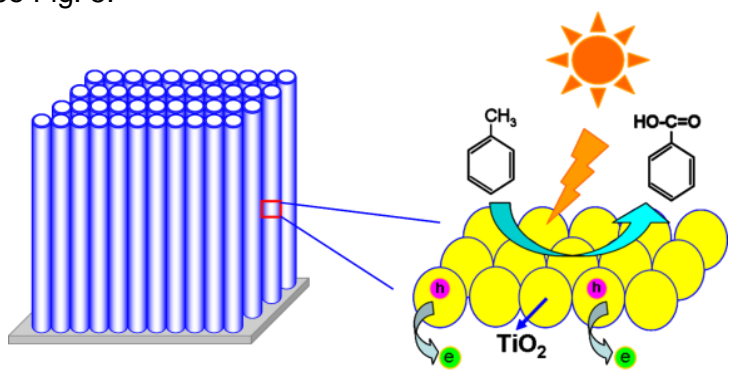

Scheme 2 Process of photocatalysis oxidation of toluene to benzoic acid at the $\mathrm{TiO}_{2}$ nanotubes electrode

\subsubsection{The coupling mechanism of solar thermal-electro- photo field driven process for benzoic acid synthesis}

The combined solar thermal-electro-photo field for benzoic acid synthesis has been shown in Scheme 3, it can be seen that, all of the energy in the reaction comes from solar energy. In the reaction, there are several groups forming at the surface of $\mathrm{TiO}_{2}$ anode, such as hydroxyl, carboxyl and $-\mathrm{O}-\mathrm{OH}$, which help to break the methyl $\mathrm{C}-\mathrm{H}$ bonds of toluene. The potential of the photovoltaic supplies by the solar thermoelectric mode is $1.0 \mathrm{~V}$, in which case the oxidation of water has been inhibited at this potential. The photocatalysis of toluene oxidation carried out at the $\mathrm{TiO}_{2}$ anode with the enhancement of the coupled solar thermal and solar electric field.

The high temperature generated by solar thermal in the solar thermoelectric pathway decreases the free energy requirement for toluene oxidation, whose electrolysis potential decreases with temperature as calculated, ${ }^{[9]}$ which means a relatively lower voltage of electrolysis at higher temperature can meet the needs of the formation of benzoic acid from toluene. An increasing rate of solar thermal usage is good to increase the efficiency of solar energy (Scheme 1). Solar thermal can supply sufficient energy to conquer the high thermodynamic barriers associated with the more energetic oxidation steps and the increase of reaction rate.

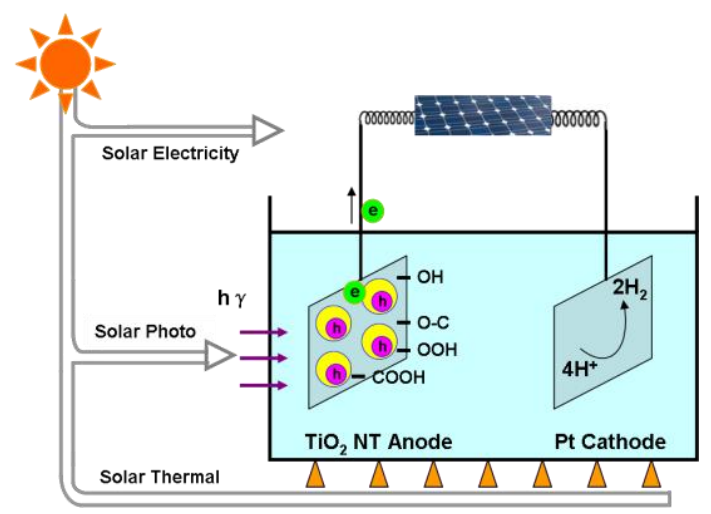

Scheme 3 Coupling mechanism of the matched field of solar thermalelectro-photo process for benzoic acid synthesis

As the analysis of $\mathrm{TiO}_{2}$ nanotubes used for anode of solar thermoelectric plus photocatalysis benzoic acid synthesis, carbon appeared on the surface of $\mathrm{TiO}_{2}$. The carbon and $\mathrm{TiO}_{2}$ have chemical bond interactions, as shown in Fig. 4, the d-orbital of $\mathrm{TiO}_{2}$ and $\pi$-orbital of carbon match well in energy levels and form $\pi-d$ electron orbital overlap that provides a convenient way to capture photogenerated charge and transport them to the surface of electrode. ${ }^{[45]}$ The emergence of $\mathrm{Ti}-\mathrm{O}-\mathrm{C}$ at $\mathrm{TiO}_{2}$ lead to an increased visible absorption and significantly enhanced photocatalytic of $\mathrm{TiO}_{2}$. ${ }^{[35]}$

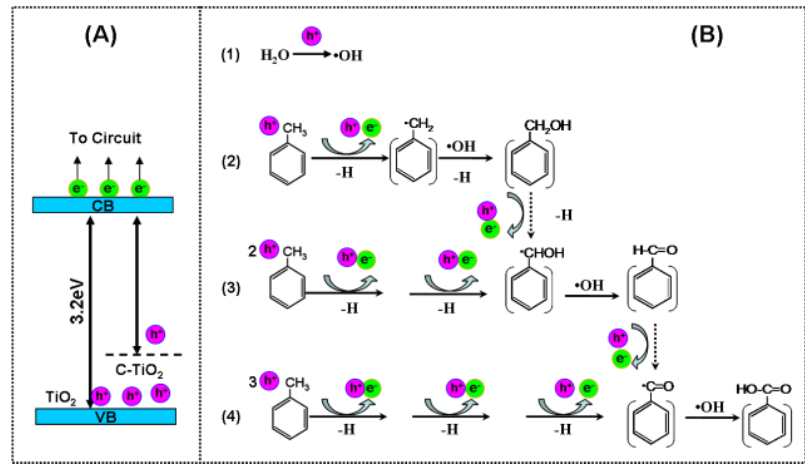

Scheme 4 Coupling mechanism of the solar electro and photo field for benzoic acid synthesis: (A) bandgap energy for pure $\mathrm{TiO}_{2}$ and $\mathrm{C}-\mathrm{TiO}_{2}$ and (B) Reaction of the photo-generated hole-electron pairs

Coupling with the electric field (generated by photovoltaic), the conversion of toluene increased to $27.7 \%$ (Table S1), which is larger than that of only the solar photo field process, $23.7 \%$ (Fig. $1 \mathrm{c})$, the photocatalytic activity of toluene oxidation at $\mathrm{TiO}_{2}$ nanotube electrode improved. The $\mathrm{TiO}_{2}$ used is an n-type semiconductor. When an electric field with potential of $1.0 \mathrm{~V}$ (supplied by photovoltaic) was applied at the $\mathrm{TiO}_{2}$ nanotube anode and platinum cathode and coupled with UV illumination, the potential of the $\mathrm{TiO}_{2}$ nanotube anode is more positive than that of the solution, the energy band beside the surface of the $\mathrm{TiO}_{2}$ anode will bend upwards, and the photo-generated electrons will move toward the conduction band, $\mathrm{CB}$, and becoming highly active electrons that enter into the circuit. While the photogenerated holes in the valence band, VB, will move toward the surface. The photo-generated holes can oxidize water to hydroxyl radicals $(\cdot \mathrm{OH})$, which are known to be the major active species during photocatalytic oxidation reactions. ${ }^{[46,47]}$ Toluene can be oxidized by these radical $\cdot \mathrm{OH}$. The photo-generated holes have a strong ability to trapping electrons, and can directly oxidize toluene by capturing electrons from the methyl $\mathrm{C}-\mathrm{H}$ bonds. The electric potential promotes the separation of photogenerated electrons and holes and prevents them from recombination so as 
to enhance the efficiency of photocatalysis; the global process is shown in Scheme 4.

The toluene oxidation at the $\mathrm{TiO}_{2}$ nanotube anode also starts with a free radical formation, ${ }^{[9]}$ the coupling of the benzyl free radicals, hydroxyl radicals from the photogenerated holes followed by intra-molecular rearrangements result in the formation of benzoic acid. A synergistic effect was found in the combination of photocatalysis, electrolysis and effect of thermal field for benzoic acid synthesis. The yield of benzoic acid increases with temperature (Fig. 2) in the combined solar thermal-electro-photo field, the solar thermal decrease the electrolysis potential of the toluene oxidation endothermic reaction and enhance kinetics to improve the reaction rate. The enhanced absorption band of $\mathrm{TiO}_{2}$ to the visible signifies a decrease in the bandgap energy. The excited-state electrons in electric field coupled photocatalysis, can be transported from the $\mathrm{TiO}_{2}$ nanoparticles upon UV illumination to the surface of carbon- $\mathrm{TiO}_{2}$ forming with the photo-generated current, which increases intensity of the electric field from solar electro, and accordingly increases the utilization of solar energy. The solar to chemical energy conversion efficiency in solar thermoelectric field for benzoic acid synthesis reaches $48.1 \%$ at the temperature of $90^{\circ} \mathrm{C}$, which is in accordance with the equation of our previous report. ${ }^{[8]}$ And after plus the effect of UV photocatalysis, the conversion runs up to $53.3 \%$ according to Scheme 1.

In summary, the synergism of the solar thermal, solar electro and photo field facilitates the oxidation of toluene at the surface of $\mathrm{TiO}_{2}$ electrode easily, with the solar thermal induced increasement of temperature more and more benzoic acid should be generated.

\section{Conclusion}

This paper presents the first application of solar thermalelectro-photo chemical process for the synthesis of a useful organic material, benzoic acid from toluene. This study sought an appropriate mode of solar energy utilization and electrode (anode) material to optimize and maximize the use of solar energy for organic synthesis. The $\mathrm{TiO}_{2}$ nanotubes electrode is used for organic synthesis for the first time. In this study, the energy from UV, visible and infrared band was used in a single reaction process, solar energy is used exclusively to drive the reaction and no other form of energy is used. Combining the effect of solar thermal, solar electro with the photocatalysis of $\mathrm{TiO}_{2}$, toluene is oxidized to benzoic acid at the surface of the $\mathrm{TiO}_{2}$ nanotubes anode. Product analysis shows that the main product is benzoic acid, and the yield of benzoic acid can be enhanced by increasing the reaction temperature (from solar thermal) with the aid of the stable solar electro (1.0V) and illumination of UV plus $\mathrm{TiO}_{2}$ nanotubes electrode.

The high temperature generated by solar thermal decreases the electrolysis potential of toluene to benzoic acid. The electric potential promotes the separation of the photogenerated electron-hole pairs and prevents their recombination. The groups, hydroxyl, carboxyl and $-\mathrm{O}-\mathrm{OH}$, grow at the surface of $\mathrm{TiO}_{2}$ nanotubes electrode after being used at the anode for benzoic acid synthesis, and facilitate the oxidation of toluene to benzoic acid. The emergence of Ti-O-C bond at $\mathrm{TiO}_{2}$ leads to an increased visible absorption and significantly enhanced photocatalytic properties of the $\mathrm{TiO}_{2}$. The yield of benzoic acid reached $11.5 \%, 20.8 \%, 26.1 \%$ at respective temperature of 30,60 and $90^{\circ} \mathrm{C}$, and the corresponding conversion of toluene reached $34.7 \%$, 55.5\%,
$62.6 \%$ respectively. The results demonstrate that the $\mathrm{TiO}_{2}$ nanotubes electrode is suitable for the synthesis of benzoic acid from toluene with the combined Solar Thermal-Electro-Photo field. The new configuration has the potential of being put into practice for the synthesis of benzoic acid from toluene, which is an important precursor for various industrial syntheses.

\section{Acknowledgements}

The research is financially supported by National Science Foundation of China (Grant No. 21376049) and the United States National Science Foundation (Grant No.123072).

\section{References}

[1] N. L.Panwar, S. C. Kaushik, S. Kothari, Renew. Sustain. Energy Rev. 15 (2011) 1513-1524.

[2] Y. Wang, A. Gu, A. Zhang, Energy Policy. 39 (2011) 6745-6759.

[3] R. Bube. Fundamentals of solar cells: photovoltaic solar energy conversion, Elsevier, 2012.

[4] S. Linic, P. Christopher, D. B.Ingram, Nat. Mater. 10 (2011) 911-921.

[5] S. Licht, B. Cui, B. Wang, F. Li, J. Lau, S. Liu, Science 345 (2014) 637-640.

[6] F. Li, S. Liu, B. Cui, J. Lau, J. Stuart, B. Wang, S. Licht, Adv. Energy Mater. 5 (2015) 1401791.

[7] B. Wang, Y. Hu, H. Wu, S. Licht, Electrochem. Sci. Lett. 2 (2013) H34.

[8] S. Licht, Adv. Mater. 23 (2011) 5592-5612.

[9] Y. Zhu, B. Wang, X. Liu, H. Wang, H. Wu, S. Licht, Green Chem. 16 (2014) 4758-4766.

[10] Y. Zhu, B. Wang, H. Wang, X. Liu, S. Licht, Solar Energy 113 (2015) 303-312.

[11] T. Guo, Z. Bai, C. Wu, T. Zhu. Appl. Catal. B-Environ. 79 (2008) 171-178.

[12] D. Kraemer, B. Poudel, H. P. Feng, J. C. Caylor, B. Yu, X. Yan, Y. Ma, X Wang, D. Wang, A. Muto, K. McEnaney, M. Chiesa, Z. Ren, G. Chen, Nat. Mater. 10 (2011) 532-538.

[13] M. Qamar, ACS Appl. Mater. Interfaces 7(2015) 1257-1269.

[14] K. Yu, J. Chen, Nanoscale Res. Lett. 4 (2009) 1-10.

[15] M. J. Jin, J. Jo, J. H. Kim, K. S. An, M. S. Jeong, J. Kim, J. W. Yoo, ACS Appl. Mater. Inter. 6 (2014) 11649-11656.

[16] I. A. Digdaya, L. Han, T. W. F. Buijs, M. Zeman, B. Dam, A. H. M. Smets, W. A.Smith, Energy Environ. Sci. 8 (2015) 1585-1593.

[17] C. Li, C. Koenigsmann, W. Ding, B. Rudshteyn, K. R. Yang, K. P. Regan, S. J. Konezny, V. S. Batista, G. W. Brudvig, C. A. Schmuttenmaer, J. H. Kim. J, Am. Chem. Soc. 137 (2015) 1520-1529.

[18] J. J. Biedrzycki, S. Livraghi, I. Corazzari, L. Mino, G. Spoto, E. Giamello, Langmuir 31 (2015) 569-577.

[19] S. Hu, M. R. Shaner, J. A. Beardslee, M. Lichterman, B. S. Brunschwig, N.S Lewis, Science 344 (6187) (2014) 1005-1009.

[20] X. Zhang, D. K. Wang, D. R. S. Lopez, J. C. D. Costa, Chem. Eng. J. 236 (2014) 314-322.

[21] C. H. Ao, S. C. Lee, Chem. Eng. Sci. 60 (2005) 103-109.

[22] J. Mo, Y. Zhang, Q. Xu, J. J. Lamson, R. Zhao, Atmos. Environ. 43 (2009) 2229-2246.

[23] X. Kang, S. Chen, J. Mater. Sci. 45 (2010) 2696-2702.

[24] J. Schneider, M. Matsuoka, M. Takeuchi, J. Zhang, Y. Horiuchi, M. Anpo, D. W. Bahnemann, Chem. Rev. 114 (2014) 9919-9986.

[25] A. Imanishi, K. Fukui, J. Phys. Chem. Lett. 5 (2014) 2108-2117.

[26] S. Ito, S. M. Zakeeruddin, R. Humphry-Baker, P. Liska, R. Charvet, P. Comte, Adv. Mater. 18 (2006) 1202-1205.

[27] J. M. Macak, H. Tsuchiya, L. Taveira, S. Aldabergerova, P. Schmuki, Angew. Chem. Int. Edit. 44 (2005) 7463-7465

[28] X. Yu, B. Kim, Y. K. Kim, ACS Catal. 3 (2013) 2479-2486.

[29] C. Y. Chen, K. Ozasa, F. Kitamura, K. Katsumatad, M. Maedab, K. Okadad, N. Matsushitad, Electrochim. Acta 153 (2015) 409-415.

[30] H. Mirabolghasemi, N. Liu, K. Lee, P. Schmuki, Chem. Commun. 49 (2013) 206720-206769.

[31] S. P. Albu, A. Ghicov, S. Aldabergenova, P. Drechsel, D. LeClere, G. E. Thompson, J. M. Macak, P. Schmuki, Adv. Mater. 20 (2008) 4135-4139.

[32] G. Socrates. Infrared Characteristic Group Frequencies, 2nd ed, John Wiley \& Sons: Sussex, U.K., 1997. 
[33] M. T. Colomer, M. J. Velasco, J. R. Jurado, J. Sol-Gel. Sci. Techn. 39 (2006) 211-222.

[34] Y. Lee, M. Kang, Mater. Chem. Phys. 122 (2010) 284-289.

[35] D. Zhao, G. Sheng, C. Chen, X. Wang, Appl. Catal. B Environ. 111-112 (2012) 303-308.

[36] S. P. Albu, H. Tsuchiya, S. Fujimoto, P. Schmuki, Eur. J. Inorg. Chem. 2010 (2010) 4351-4356

[37] F. Zuo, L. Wang, T. Wu, Z. Zhang, D. Borchardt, P. Feng, J. Am. Chem. Soc. 132 (2010) 11856-11857.

[38] I. Paramasivam, H. Jha, N. Liu, P. Schmuki, Small 8 (2012) 3073-3103.

[39] K. Lee, D. Kim, P. Roy, I. Paramasivam, B. I. Birajdar, E. Spiecker, P. Schmuki, J. Am. Chem. Soc. 132 (2010) 1478-1479.

[40] M. Iqbal, An introduction to solar radiation, Elsevier, 2012.

[41] S. Licht, G. Hodes, R. Tenne, J. Manassen, Nature 326 (1987) 863-864.

[42] M. A. Green, K. Emery, Y. Hishikawa, E. D. Dunlop, Prog. Photovolt: Res. Appl. 23 (2015) 1-9.

[43] B. Zhu, Q. Guo, X. Huang, S. Wang, S. Zhang, S. Wu, W. Huang, J. Mol. Catal. A-Chem. 249 (2006) 211-217.

[44] H. Wu, Y. Wang, Y. Ma, T. Xiao, D. Yuan, Z. Zhang, Ceram. Int. 41 (2015) 2527-2532.

[45] W. Tu, Y. Zhou, Q. Liu, S. Yan, S. Bao, X. Wang, M. Xiao, Z. Zou, Adv. Funct. Mater. 23 (2013) 1743-1749.

[46] J. Tripathy, K. Lee, P. Schmuki, Angew. Chem. Int. Ed. 53 (2014) 1260512608.

[47] Z. Jiang, H. Wang, H. Huang, C. Cao, Chemosphere 56 (2004) 503-508.

Received: ((will be filled in by the editorial staff))

Published online: ((will be filled in by the editorial staff 


\section{Graphical Abstract}

Solar thermoelectric field plus photocatalysis for efficient organic synthesis exemplified by toluene to benzoic acid

Y. J. Zhu ${ }^{\dagger}$, H. Y. Wang ${ }^{\dagger}$, Prof. B. H. Wang, X. L. Liu, H. J. Wu, and Prof. S. Licht ${ }^{\star}$

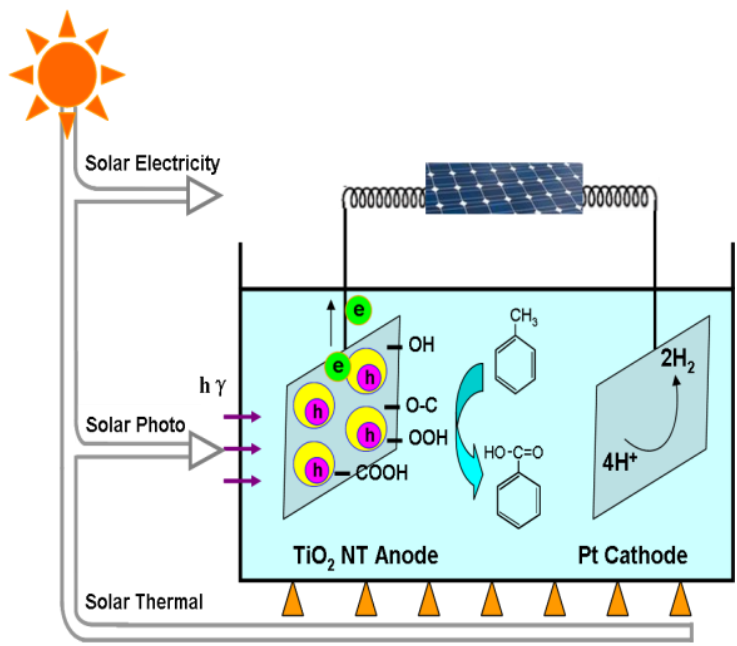

